\title{
EFFICACY OF EMOTIONAL INTELUGENCE TECHNIQUE AND PARENTAL SOCIAL CLASS IN FOSTERING VOCATIONAL DEVELOPMENT OF SECONDARY SCHOOL STUDENTS IN GOMBE STATE, NIGERIA
}

\author{
Muraina Kamilu Olanrewaju ${ }^{1}$, Yusuf Suleiman ${ }^{2}$ \\ ${ }^{1}$ Legacy University, Banjul, Gambia; ${ }^{2}$ Unicaf University, Larnaca, Cyprus
}

muraina_kamilu@yahoo.com; yusufsuleiman96094@gmail.com

First draft received: 12 Oct 2018 Date Accepted: 21 Dec 2018 Final proof received: 18 Feb 2019

Abstract
This study focused on efficacy of emotional intelligence technique and parental social class in fostering
vocational development of secondary school students in Gombe State, Nigeria. Pretest-posttest, control
group quasi-experimental design with a $2 \times 3$ factorial matrix was used in the study. Multi-stage sampling
technique was used in sampling 117 participants from 3 local government areas (12 schools) in the state.
The respondents were measured with validated scale of 0.79 reliability coefficient and the data obtained
was analyzed using $t$-test and analysis of variance (ANOVA). Two (2) research hypotheses were
formulated and tested at 0.05 level of significance. The results showed that there was significant difference
in the vocational development of secondary school students exposed to emotional intelligence technique
and those in the control group (t= $57.64 ;$ p $<0.05)$ and there was significant difference in the vocational
development of secondary school students with high, moderate, and low parental social class (t= $27.51 ;$
p<0.05). In view of these results, the study recommended that educational stakeholders should intensify
their effort to organize conferences on the implications of emotional intelligence technique and parental
social classes on effective re-orientation of youths towards improving vocational development.
Keywords: Emotional intelligence technique; secondary school students; social class; vocational
development

\section{INTRODUCTION}

The origin of emotional intelligence could be traced back to Charles Darwin's work on the importance of emotional expression to survival and successful adaptation. In the 1900s even though traditional definitions of intelligence emphasized cognitive aspects such as memory and problem- solving, several influential researchers in the intelligence field of study had begun to recognize the importance of non-cognitive aspects. For instance, as early as 1920, Thorndike used the term social intelligence to describe the skill of understanding and managing other people (Hein, 2005; Petrides, SanchezRuiz, Siegling, Saklofske, Mavroveli, 2018).

Vocation development is the activity, trade or occupation and others constituting a life style expressed in time, energy, and activity. It simply refers to a type of work or way of life that an individual believes he or she is specifically suited for. Vocation development can be said to reflect one's calling to a particular business or profession. It is an occupation to which an individual's life is committed and has inherent liking and feeling for the work. In a developing country like Nigeria, which is at the verge of changing from a traditionally agricultural country to an industrial one, the choice of a vocation is a complex task. The longer years of apprenticeship to the family trade such as weaving, carving, and fishing are being replaced by years of formal education in primary and secondary schools with resultant effect that the children may not take up their parents' trade (Ayogu, 2015; Omeje, 2010; Hoffmann, Ivcevic \& Brackett, 2018). In the same vein, vocation is a profession, occupation, employment by which one earns his or her living, especially one for which s/he has a period of training in an institution or through apprenticeship. Vocational development is very important to every nation, especially a developing nation like Nigeria (Omeje, 2010). Omeje added that people need to have the knowledge and information on national manpower resources, requirements, analysis, trends in employment and unemployment. The choice of a 
vocation therefore is one of the most important decisions one makes in life. The issue of vocational development has attracted the interest of many individuals and government. Vocational development or choice is a developmental process and spans almost through person's life time (Ohiwerei \& Nwosu, 2009). The choice determines satisfaction one expects to get from his work and the opportunities he has for promotion and advancement. Individual social status, income, life style, choice of friends, mental and physical health is influenced by the type of work he or she does. In other words a person's vocational choice or preference plays an important role in his entire life. Kemjika (1995) observed that most students have insufficient information about different jobs, courses of study and other activities. They are thus unable to judge whether their choices are reasonable. Without detailed and adequate information about occupations, students many jump blindly into jobs to become frustrated and unhappy later in life and perhaps at such times when a retreat would no longer be easy or possible (Omeje, 2010).

The current mass unemployment in Nigeria is threatening the vocational development of school leavers. Secondary school students are expected to choose their careers in the senior secondary school. More often than not students rush to parents for guidance as to which subject and career to choose. In most cases, the choice of careers, subjects, and courses of study and the subsequent career paths to follow are a nightmare for prospective adolescents. Most often, choosing the right subject combination leading to the right profession can make the difference between enjoying and detesting the career in future (NUR, 2017). Despite the activities of the guidance counsellors posted to the secondary schools by both the Federal and State governments in Nigeria, to carry out vocational, educational and personal-social counselling, most secondary school students and adolescents were usually not vocationally mature by the time they leave school. There are evidences that most of the students leave secondary schools quite deficient in occupational information (Arhedo, Adomeh \& Aluede, 2009; Ohiwerei \& Nwosu, 2009; Muraina \& Muraina, 2015). The consequences of unrealistic vocational choice and vocational development have been failure of students to enter appropriate higher institutions to pursue courses of their choice, frustration, having to drop out of school, inability to get employed because of lack of relevant job requirements and qualifications, and poor vocational adjustment on employment (Akpochafo, 2018; Ekechukwu \& Eze, 2016).

In view of the foregoing, this study focused on the efficacy of emotional intelligence technique and parental social class in fostering vocational development of secondary school students in Gombe State, Nigeria.

Over the years, a lot of research efforts have been made in the area of vocational development to understand the problem of vocational development (Cohen, Chartrand, \& Jowdy, 2005; Owoyele \& Muraina, 2015). Some research efforts have focused on identifying some correlates of vocational development, especially on ego identity (Adeyemo, 1996; Asuzu, 1998). Majority of the available studies did not address vocational development, despite the enormity of the problem among adolescents. Also, researchers on vocational development mostly concentrated on descriptive survey research with few experimental studies also available globally.

\section{EMOTIONAL INTELLIGENCE AND PARENTAL SOCIAL CLASS IN THE CONTEXT OF VOCATIONAL DEVELOPMENT}

Emotional intelligence develops over a person's life span and could be enhanced through training and teaching and learning in formal educational contexts (Jaeger, 2013; Chernyshenko, Kankaras \& Drasgow, 2018; Stillman, Stillman, Martinez, Freedman, Jensen \& Leet, 2018). Emotional intelligence is generally regarded as a factor with the potential to contribute to more positive attitudes, behaviours and outcomes and has been related to career success (Goleman, 2013). Researchers and career counsellors have also recognised the significance of emotional intelligence in career success, career satisfaction and well-being (Kidd, 2008). No wonder, Pool and Sewell (2007) further regard the development of emotional intelligence as desirable for enhancing individuals' employability and vocational development. Emotional intelligence technique positively relates to less dysfunctional career thinking, greater career decision-making self-efficacy, a higher level of willingness to explore a variety of vocational development, and to commit to attractive career options (Puffer, 2011).

Emotional intelligence technique is also positively associated with important employment experiences and their emotional attachment to their current careers and jobs (Ayogu, 2015). Emotional intelligence technique is positively related to less dysfunctional career thinking, greater career decision-making, self-efficacy and a higher level of willingness to explore a variety of vocational development and to commit to attractive career options (Puffer, 2011). Salovey and Mayer's (1990) model proposes that emotional intelligence technique consists of a set of four conceptually related mental processes: efficiently handling psychological and social problems, accurately appraising and expressing emotion in the self and others, regulating emotion in the self and others, and using emotions adaptively in order to solve problems and achieve one's goals. The ability to monitor one's own emotional landscape is thought to lead to greater insight and self-knowledge (Goleman, 2013). Salovey and Mayer (1990) opined that students differ in the degree to which they display their vocational development. Individuals who appraise and express (perceive and respond to) their emotions accurately are likely to be better understood by the people with whom they interact.

The moderating variable in this study is parental social class. Parental social class is the parental level of incomes, occupation and educational qualification which may/may not influence the student's vocational development. Growing up in poverty affects nearly every 
facet of development in students and adolescents (Beegle, 2007). Families in poverty experience underemployment, low levels of education, single parental social class, inadequate medical care, low access to childcare, drug and alcohol addictions, and unsafe neighborhoods (Falaye \& Adams, 2008). Economic stress due to poverty negatively impacts quality of parental social class, familial interactions, and child's adjustment, which in turn increases adolescents' risk for loneliness, depression, unruly behaviour, and substance use (Conger, Ge, Elder, Lorenz and Simons, 2004; Lempers, Clark-Lempers and Simmons, 2009). Because of this, poverty can work against the best efforts of wellmeaning parents and students' vocational development (VanTassel-Baska, 2010).

Social class affects students on many components of vocational development, including self-relevant information, opportunity structure, and level of stress (Phillips \& Pittman, 2013). Self-relevant information is information about oneself received from encounters with others. The stigma of poverty is such a powerful force that the associated shame and embarrassment due to marginalization may result in adolescents' inability to maintain positive views of themselves. This decrease in confidence and feelings of agency may prove harmful to the final stages of vocational development because internalizing such negative self-relevant information can result in lowered morale (Muraina \& Muraina, 2015; Owoyele \& Muraina, 2015). These negative feelings can impinge on exploration and eventually vocational development (Beegle, 2007; Phillips \& Pittman, 2013). Regarding opportunity structure, research has repeatedly shown that social class is associated with limited life opportunities and constrained scope of aspirations for one's future (Figueira-McDonough, 2008; Powers, 2016). Professional and educational aspirations can be limited by poverty (Phillips \& Pittman, 2013). Expectations for jobs and careers are directly linked to social class (Cookson \& Persell, 2005). Adolescents in social class form expectations for their jobs based on their parents' jobs and by others around them (Muraina and Muraina, 2015).

Taken together, the present study focused on efficacy of emotional intelligence technique and parental social class in fostering vocational development of secondary school students in Gombe State, Nigeria.

The main objective of this study is to examine the efficacy of emotional intelligence technique and parental social class in fostering vocational development of secondary school students in Gombe State, Nigeria. Specifically other objectives include to: 1) find out the difference in the vocational development of secondary school students exposed to emotional intelligence technique and those exposed to conventional lecture method; and 2) investigate the difference in the vocational development of secondary school students with high, moderate and low parental social class

\section{Research Hypotheses}

The following null hypotheses were formulated to guide the study:
$\mathrm{HO}_{1}$ : There is no significant difference between the vocational development of secondary school students exposed to emotional intelligence technique and those exposed to conventional lecture method

$\mathrm{HO}_{2}$ : There is no significant difference between the vocational development of secondary school students with high, moderate, and low parental social classes.

\section{METHODOLOGY}

\section{Population/Sampling Technique}

The study adopted the pretest-posttest, control group quasi-experimental design with a $2 \times 3$ factorial matrix. In essence, the row consists of emotional intelligence technique and the control. The row was crossed with parental social class varied at three levels (High, Moderate, and Low). The population for the study comprised 21,360 public secondary school students in 11 Local Government Areas (LGAs) of Gombe State, Nigeria (TESCOM, 2017).

Multi-stage sampling technique was used for the study. The first stage involved the use of simple random sampling technique to select 3 LGAs. The second stage witnessed the selection of 4 public secondary schools from each sampled LGAs. Ten secondary school students were sampled in each school through balloting and this cut across different social class. On the whole, 120 secondary school students were drawn for the study. However, the whole population was grouped into two, one group formed emotional intelligence technique class and the remaining one served as control group.

\section{Instrument}

(a) Parental Social Class Scale: Social class scale developed by Muraina and Muraina (2015) was adopted to measure the parental social class of the students. This scale was based on their parents' occupation, educational level, residence and types of equipment in the house. The items contain twelve (12) items to measure the social class. The point from the scale further divided into three parts in the scorings; lower social class, moderate and high social classes. The test retest reliability of the scale was given as 0.73 . The score below 25 showed low social class, 26-50 moderate and the score above 50 demonstrated high social classes after the summed up score of the scale across the items. The researcher obtained Cronbach alpha value of 0.90 for the scale which has helped to ascertain its adaptability and suitability after a pilot study.

(b) Vocational Development Scale: Vocational development choice scale developed by Muraina and Owoyele (2015) was used to measure the vocational development of the participants. The scale consists of twenty (20) items aimed at unveiling the respondents' level of vocational development. The items were built on a 4 point scales which are: 1 (never), 2 (seldom), 3 (sometimes) to 4 (always). To establish the reliability of the scale, the internal consistency was computed and Cronbach's alpha of .83 was obtained. The following 
criteria were used in selecting the participants for the study:

i. Participants should be bonafide students of secondary schools in Gombe State

ii. Participants with consent form from the school selected

iii. Participants willing to participate in the treatment programme.

iv.Participants should be within 11-21 years of age

\section{Method of Data Collection/Analysis}

The study was carried out in four phases: pre-sessional activities, pre-test, treatment and post-test. At the presession, activities included the screening, recruitment and assignment of participants to the experimental and control group. Advertisement was made to request for participants in the university. A preliminary meeting was organised to familiarise with the interested participants and to solicit their willingness to participate in the study. At the pre-test stage, vocational development and parental social class scales were administered to the participants. Participants in the experimental group only were exposed to 8 sessions of treatment. Each session spanned for an average of 60 minutes. Though the control group was not treated, they were exposed to a lecture titled "Education Access and Demand in Nigeria". The post-test was administered following the conclusion of the programme.

$T$-test and Analysis of Variance (ANOVA) statistical analysis were employed to analyse the data in this study. T-test was used to establish any significant difference in the vocational development of participant in treatment group and control while ANOVA was used to establish the significant difference among parental social class level.

\section{RESULTS}

The study examined the efficacy of emotional intelligence technique and parental social class in fostering vocational development of secondary school students in Gombe State, Nigeria. Two (2) null hypotheses were formulated and tested at 0.05 level of significance. The results are presented in tabular form: Hypothesis One: There is no significant difference between the vocational development of secondary school students exposed to emotional intelligence technique and those in the control group

Table 1: T-test of Students Exposed to Emotional intelligence technique and those exposed to Conventional Lecture Method

\begin{tabular}{|c|c|c|c|c|c|c|c|c|}
\hline Groups & $\mathbf{N}$ & Mean & SD & Std. Error & DF & $T$ & $\mathbf{p}$ & Remark \\
\hline $\begin{array}{l}\text { Emotional } \\
\text { Intelligence }\end{array}$ & 57 & 62.32 & 14.18 & 3.61 & 115 & $57.64^{*}$ & 0.00 & ${ }^{*} S$ \\
\hline $\begin{array}{l}\text { Lecture } \\
\text { Method }\end{array}$ & 60 & 34.97 & 9.64 & 2.17 & & & & \\
\hline
\end{tabular}

* Significant at $p<0.05$

The result in table 1 showed that there was significant difference between the vocational development of secondary school students exposed to emotional intelligence technique and those in the control group ( $t=$ $57.64 ; p<0.05)$. The mean value of the table further revealed that the students in emotional intelligence technique had higher vocational development than their counterpart in the control group. This further meant that the treatment had significant influence on vocational development of secondary school students.

Hypothesis Two: There is no significant difference between the vocational development of secondary school students with high, moderate and low parental social class

Table 2: Summary of t-test of students with high, moderate and low parental social class

\begin{tabular}{|c|c|c|c|c|c|c|c|c|}
\hline Groups & $\mathbf{N}$ & Mean & SD & Std. Error & DF & $\mathbf{F}$ & $p$ & Remark \\
\hline High & 29 & 41.86 & 7.63 & 2.52 & & & & \\
\hline Moderate & 19 & 37.75 & 5.79 & 2.07 & 115 & $27.51^{*}$ & 0.01 & * $S$ \\
\hline Low & 69 & 25.93 & 4.72 & 1.80 & & & & \\
\hline
\end{tabular}

* Significant at $p<0.05$

Table 2 shows that there was significant difference between the vocational development of secondary school students with high, moderate and low parental social class $(t=27.51 ; p<0.05)$. The mean value of the table further revealed that the students with high parental social class had higher vocational development than their counterpart with moderate and low parental social class. This further meant that parental social class had significant influence on vocational development of secondary school students. 


\section{DISCUSSION}

The result in Table 1 shows that there was significant difference between vocational development of secondary school students exposed to emotional intelligence technique and those in the control group. The mean value of the table further revealed that the students in emotional intelligence technique had higher vocational development than their counterpart in the control group. This further meant that the treatment has significant influence on vocational development of secondary school students. In line with this finding, Emotional intelligence is generally regarded as a factor with the potential to contribute to more positive attitudes, behaviours and outcomes and has been related to career success (Goleman, 2013). Researchers and career counsellors have also recognised the significance of emotional intelligence in career success, career satisfaction and well-being (Kidd, 2008). Also, Pool and Sewell (2007) further found that development of emotional intelligence as desirable for enhancing individuals' employability and vocational development. Emotional intelligence technique positively relates to less dysfunctional career thinking, greater career decision-making self-efficacy, a higher level of willingness to explore a variety of vocational development, and to commit to attractive career options (Puffer, 2011). Emotional intelligence technique is also positively associated with important employment experiences and their emotional attachment to their current careers and jobs (Ayogu, 2015; Chernyshenko Kankaraš, \& Drasgow, 2018). Emotional intelligence technique is positively related to less dysfunctional career thinking, greater career decision-making, selfefficacy and a higher level of willingness to explore a variety of vocational development and to commit to attractive career options (Puffer, 2011).

The result of Table 2 revealed that there was significant difference between the vocational development of secondary school students with high parental social class and those with low parental social class. The mean value of the table further revealed that the students with high parental social class had higher vocational development than their counterpart with low parental social class. This further meant that parental social class had significant influence on vocational development of secondary school students. This is consistent with the study of Quint, Griffin, Kaufman, Landers, and Utterback (2018) who found that families in poverty experience under-employment, low levels of education, single parental social class, inadequate medical care, low access to childcare, drug and alcohol addictions, and unsafe neighborhoods. Economic stress due to poverty negatively impacts quality of parental social class, familial interactions, and child's adjustment, which in turn increases adolescents' risk for loneliness, depression, unruly behaviour, and substance use (Conger et al., 2004; Lempers, Clark-Lempers, \& Simmons, 2009). Because of this, poverty can work against the best efforts of well-meaning parents and students' vocational development (VanTassel-Baska, 2010). Social class affects students on many components of vocational development, including selfrelevant information, opportunity structure, and level of stress (Phillips \& Pittman, 2013). The stigma of poverty is such a powerful force that the associated shame and embarrassment due to marginalization may result in adolescents' inability to maintain positive views of themselves. This decrease in confidence and feelings of agency may prove harmful to the final stages of vocational development because internalizing such negative self-relevant information can result in lowered morale (Muraina \& Muraina, 2015; Owoyele \& Muraina, 2015).

\section{CONCLUSIONS AND RECOMMENDATIONS}

Vocational development is a core developmental challenge for adolescents and emerging adults. Establishing a strong sense of identity provides individuals with a sense of continuity and sameness, and plays favourably into psychosocial functioning. However, identity confusion is associated with a disorganized or haphazard sense of self. Identityconfused individuals seem to be out of touch with their inner needs and lack the energy to invest in identityrelated exploration and to commit to life-defining choices. Abundant research to date focused on processes and correlates of vocational development in adolescence and the transition to adulthood. Based on the findings of this study, persistent low vocational development of Nigerian secondary school students needs not to continue indefinitely. There is hope that with the improvement of parental social class and emotional intelligence technique skill, the situation can be changed for the better. The issue of vocational development has attracted the interest of many individuals and government. Career development or choice is a developmental process and spans almost through person's life time. The choice determines satisfaction one expects to get from his work and the opportunities he has for promotion and advancement. Individual social status, income, life style, choice of friends, mental and physical health is influenced by the type of work he or she does. In other words a person's vocational choice or preference plays an important role in his entire life.

Educational stakeholders should intensify their effort to organize seminars/conferences on the implications of emotional intelligence technique as effective interventions towards enhancing vocational development among secondary school students.

Education planners should introduce vocational education in secondary schools. This is worthwhile because vocational education extends the academic world to the world of work. Teachers should emphasis during their lesson, the career implications of subjects so that student will see how individual subjects relate to existing careers thus increasing their knowledge of occupations. Teachers and other stakeholders in the school system are to be trained on how to handle the case of students with low parental social class. This will serve as collaborative efforts to assist the students in overcoming the challenges of low vocational 
development among secondary school students. The students in the school should be encouraged and trained on the effective usage of these interventions (emotional intelligence technique). This will make the students to adopt effective attitude towards enhancing their vocational development.

\section{REFERENCES}

Adeyemo, D. A. (1996). The didactic mode of career education and values clarification as strategies in fostering the vocational maturity of Nigerian adolescents. (Unpublished PhD Thesis), University of Ibadan, Ibadan.

Adeyemo, D. A. (1998). Effects of didactic mode of career education and values clarification on the career-decision-making self-efficacy of secondary school students. Nigerian Journal of Applied Psychology, 4(1), 1-15.

Akpochafo, G. O. (2018). Career development interventions implemented by counselors in secondary schools in Delta State of Nigeria. Journal of Emerging Trends in Educational Research and Policy Studies, 9(2), 40-44.

Arhedo, P. A., Adomeh, I. O., \& Aluede, O. (2009). School counsellors' roles in the implementation of universal basic education [UBE] scheme in Nigeria. Edo Journal of Counselling, 2(1), 58-65.

Asuzu, C. C. (1998). Efficacy of covert self-control and emotional intelligence technique in treatment of promiscuity among adolescents in Ibadan. (Unpublished PhD Thesis). University of Oyo State, Nigeria.

Ayogu, D. U. (2015). Emotional intelligence and implication for career development in selected federal universities in South East, Nigeria. (Unpublished PhD Thesis). University of Nigeria, Nsukka.

Beegle, D. (2007). See poverty be the difference. Tigard: Oregon Communication across Barriers Inc.

Chernyshenko, O. S., Kankaraš, M., \& Drasgow, F. (2018). Social and emotional skills for student success and well-being. New York: Springer.

Cohen, R, Chartrand, K., \& Jowdy, N. (2005). Identity and poverty: Defining a sense of self among urban adolescents. New York: Garland Publishing.

Conger, R. D., Ge, X., Elder, G. H., Lorenz, F. O., \& Simons, R. L. (2004). Economic stress, coercive family process, and developmental problems in adolescents. Child Development, 65, 541-561.

Cookson, P., \& Persell, C. (2005). Preparing for power: America's elite boarding schools. New York: Basic Books.

Crouch, N. S., \& Neilson, H. K. (2009). Understanding the effects of parental extrinsic versus intrinsic goal promotion on adolescent ethnic prejudice. Journal of Social Psychology, 3, 125-139.

Ekechukwu, R. O., \& Eze, A. F. (2016). ICT: An indispensable tool in effective guidance/counselling services for sustainable educational development in secondary schools in the 21st century in Imo
State, Nigeria. European Journal of Education Studies, (3) 45-58.

Falaye, F. W., \& Adams, B. T. (2008). An assessment of factors influencing career decisions of in-school youths. Pakistan Journal of Social Sciences, 5(3): 222- 225.

Figueira-McDonough, J. (2008). Environment and interpretation: Voices of young people in poor inner-city neighborhoods. Youth and Society, 30, 123-163.

Goleman, D. (2013). Working with emotional intelligence. Accessed 15/12/2009 from http://www.bizsum.com

Goodey, R. B. (2007). The psychological sense of school membership among adolescents: scale development and educational correlates. Psychology in the Schools, 30, 79-90.

Hammed, T. A. (1999). Fostering Interpersonal Skills among Selected Bank Workers through Assertiveness Training and Transational Analysis. (Unpublished PhD Thesis). University of Ibadan, Oyo State, Nigeria.

Hein, F. N. (2005). Race, race-based discrimination, and health outcomes among African-Americans. Annual Review of Psychology, 58, 201-225.

Hoffmann, J. D., Ivcevic, Z., \& Brackett, M. A. (2018). Building emotionally intelligent schools: From preschool to high school and beyond. In Emotional Intelligence in Education (pp. 173-198). Cham: Springer.

Kemjika, J. K. (1995). Interpersonal identity and social capital: The importance of commitment for low income, rural, African American adolescents. Journal of Black Psychology, 32(2), 219-242.

Kidd, J. M. (2008). Exploring components of career wellbeingand the emotions associated with significant career experiences. Journal of Career Development, 35(2), 166-186.

Lempers, S. D., Clark-Lempers, A. J., \& Simmons, T. K. (2009). Self-theorists, identity status, and social cognition. In D.K. Lapsley and F. C. Power (Eds.), Self-ego and identity: Integrative approaches (pp. 243-262). New York: Springer-Verlag.

Mullins, N. Z. (2005). College as a transition to adulthood.In G. R. Adams, and M. D. Berzonsky (Eds.), Blackwell handbook of adolescence (pp. 149-172). Malden, MA: Blackwell.

Muraina, M. B,, \& Muraina, K. O. (2015). Peer pressure and parental social class on cybercrime habit among university undergraduates in Southwestern Nigeria. International Journal of Technology in Teaching and Learning, 11(1), 50-59.

Nigeria Unemployment Rate (May 18, 2017). Trading Economics Retrieved from http://www.tradingeconomics.com/nigeria/unemplo yment-rate.

Ohiwerei, J. R., \& Nwosu, I. J. (2009). Social status determinants of control in individual's accounts of their mental illness. Social Science and Medicine, $55,949-61$. 
Omeje, J. C. (2010). Educational and occupational information in counselling: $A$ fundamental approach. Nsukka: Chuka Educational Publishers.

Owoyele, J. W., \& Muraina, K. O. (2015). Predictive Influence of Parental Factors on Career Choice Among School-going Adolescents in South-West, Nigeria. Academic Journal of Counselling and Educational Psychology (AJCEP), 1(1), 172-184.

Petrides, K. V., Sanchez-Ruiz, M. J., Siegling, A. B., Saklofske, D. H., \& Mavroveli, S. (2018). Emotional Intelligence as Personality: Measurement and Role of Trait Emotional Intelligence in Educational Contexts. In emotional intelligence in education (pp. 49-81). Cham: Springer.

Phillips, T. M., \& Pittman, J. F. (2013). Identity processes in poor adolescents: Exploring the linkages between economic disadvantage and the primary task of adolescence. Identity: An International Journal of Theory and Research, 3(2), 115-129.

Pool, K. R., \& Sewell, S. L. (2007). Role of Race and social class in development. Implications for counselling Psychology, in Brown, S.D \& Lent R.W (Eds) Handbook of counselling psychology (pp. 379 -408). New York, NY: John Wiley.
Powers, D. (2016). Social background and social context effects on young men's idleness transitions. Social Science Research, 25, 50-72.

Puffer, F. C. (2011). Early predictors of career development; a ten - year follow - up study, Journal of Vocational Behaviour, 70, 61 - 71.

Quint, J., Griffin, K. M., Kaufman, J., Landers, P., \& Utterback, A. (2018). Experiences of parents and children living in poverty: A review of the qualitative literature. OPRE Report 2018-30. Washington, DC: Office of Planning, Re-search, and Evaluation, Administration for Children and Families, U.S. Department of Healthand Human Services.

Salovey, S. D., \& Mayer, K. R. (1990). The Intelligence of Emotional Intelligence. Intelligence Journal, 17, 433-442.

Stillman, S. B., Stillman, P., Martinez, L., Freedman, J., Jensen, A. L., \& Leet, C. (2018). Strengthening social emotional learning with student, teacher, and schoolwide assessments. Journal of Applied Developmental Psychology, 55, 71-92.

VanTassel-Baska, F. H. (2010). The identity status field re-reviewed: An update of unresolved and neglected issues with a view on some alternative approaches. Developmental Review, 19, 497-556. 